\title{
To PEEP or not to PEEP?
}

\author{
K M Bartholomew, K G Brownlee, S Snowden, P R F Dear
}

\begin{abstract}
It is well recognised that reducing positive end expiratory pressure (PEEP) leads to an increase in the tidal volume and minute volume in ventilated neonates. The magnitude of this effect is perhaps not commonly appreciated, however. Effectively, PEEP is four times as potent as peak inflation pressure (PIP) in bringing about changes in tidal volume. The influence of changes in PEEP and PIP on tidal volume and the relative magnitude of each are considered.

Twenty one preterm infants were studied on 38 separate occasions. All were sedated, paralysed, and ventilated, 19 for hyaline membrane disease. A $1 \mathrm{~cm} \mathrm{H}_{2} \mathrm{O}$ reduction in PEEP was twice as potent as a $2 \mathbf{c m ~} \mathrm{H}_{2} \mathrm{O}$ increase in PIP in achieving an increase in tidal volume $(14 v 7 \%)$. Similarly, increasing PEEP by $1 \mathrm{~cm} \mathrm{H} \mathrm{H}_{2} \mathrm{O}$ was twice as effective as a $2 \mathrm{~cm} \mathrm{H}_{2} \mathrm{O}$ decrease in PIP in reducing tidal volume $(13 v 6 \%)$.

Small (0.5-1 cm $\left.\mathrm{H}_{2} \mathrm{O}\right)$ changes in PEEP can often be used to improve ventilation and carbon dioxide elimination. Levels of PEEP of 4-5 $\mathrm{cm} \mathrm{H}_{2} \mathrm{O}$ may, at times, impair gas exchange and contribute to overdistension.

(Arch Dis Child 1994; 70: F209-F212)
\end{abstract}

Positive end expiratory pressure (PEEP) has been used to improve oxygenation in infants ventilated for hyaline membrane disease since the early 1970s. A deficiency of surfactant results in alveolar instability and collapse. Under these conditions the application of PEEP splints the airway open, stabilises the alveoli, and prevents further atelectasis.

Some of the effects of PEEP on tidal volume have already been described. ${ }^{1-4}$ The impact of apparently inconsequential alterations in PEEP may not be fully appreciated in terms of the quantitative influence on tidal volume and arterial carbon dioxide tension $\left(\mathrm{PaCO}_{2}\right)$. The comparative effect on tidal volume of alterations in peak inflation pressure (PIP) relative to PEEP have not been reported and this may be of clinical importance when improvements in carbon dioxide exchange are sought.

It has been shown in infants dying of hyaline membrane disease that high end expiratory pressures can cause alveolar hypoventilation. The reason for this is that there is a reduction in tidal volume and consequently minute ventilation, given that other variables of ventilation remain constant. ${ }^{12}$

In this study we have attempted to quantify, in percentage terms, the influence of PEEP and PIP on tidal volume and to compare the relative effect of each as a means of regulating tidal volume and carbon dioxide exchange.

\section{Patients and methods}

PATIENTS

Twenty one preterm, ventilated infants were studied. Nineteen had hyaline membrane disease of varying severity, and two had apnoea of prematurity, one with marked growth retardation. All were receiving muscle relaxants, were sedated with alfentanil according to the unit policy, and were haemodynamically stable with acceptable arterial blood gases at the time of study.

The median birth weight was $1200 \mathrm{~g}$, range $540-2290 \mathrm{~g}$, the median gestational age was 29 weeks with a range of 25-35 weeks, and the mean (SD) age at the time of study was 45 (32) hours. The table gives the individual details of each infant.

Sixteen of the infants were ventilated with a Draeger Babylog 8000 and five with a Sechrist infant ventilator. Nineteen infants had received one or more doses of artificial surfactant in the form of artificial lung expanding compound (ALEC).

The study was approved by the local research (ethics) committee and parental consent was obtained in each case. 


\section{METHOD}

Airway pressure was measured from a side port in the endotracheal tube connector using an Insight 2000 monitor and the flow was measured using a Fleisch 00 pneumotachograph inserted between the endotracheal tube connector and the ventilator tubing. The pneumotachograph, dead space $1.7 \mathrm{ml}$, was heated and was linear for gas flows of up to 157 $\mathrm{ml} / \mathrm{s}$.

The flow signal (that is, pressure differential) was transduced, amplified (Gould), and transmitted to a PC synchronously with the pressure signal. The sampling rate was 100 $\mathrm{Hz} /$ channel.

Integration of the flow signal to volume was performed by the software and pressurevolume loops were displayed and captured for successive individual breaths.

Starting from the initial ventilator settings a series of discrete PEEP and PIP changes was made. Measurements of tidal volume and compliance were made over $30-60$ breaths at each different setting. The order in which pressure changes were made was random that is, whether the series of PIP or PEEP changes was made first.

The sequence of PIP manipulations consisted of a $2 \mathrm{~cm} \mathrm{H}_{2} \mathrm{O}$ increase in PIP, a return to the starting PIP, a $2 \mathrm{~cm} \mathrm{H}_{2} \mathrm{O}$ decrease in PIP, and a return to the starting PIP. The PEEP manipulations started with one, two, or three successive decreases of $1 \mathrm{~cm}$ $\mathrm{H}_{2} \mathrm{O}$ each, then a return to the starting PEEP. These were followed by one, two, or three $1 \mathrm{~cm} \mathrm{H}_{2} \mathrm{O}$ PEEP increases, as tolerated, and a final return to the initial settings. Only one change was made at a time and all measurements at each setting were completed before a subsequent change was made.

Each infant was monitored with an electrocardiograph and a pulse oximeter, and 12 had an intravascular arterial oxygen tension $\left(\mathrm{PaO}_{2}\right)$ catheter in situ. Any manipulation that was detrimental to the infant, in terms of a proportionately large decrease in tidal volume accompanied by a decrease in saturation, was abandoned.

Towards the end of the study, and as a separate procedure, a series of arterial blood gas measurements was attempted in 12 stable infants, following a PIP increase of $2 \mathrm{~cm} \mathrm{H}_{2} \mathrm{O}$ and a PEEP decrease of $1 \mathrm{~cm} \mathrm{H}_{2} \mathrm{O}$ in random order, returning to the starting settings between each change. Arterial sampling (from an indwelling catheter) was performed 20 minutes after each pressure change to allow for gas equilibration, and no other changes or nursing interventions were made during this period. The pneumotachograph was not in the circuit while these measurements were made as the extra dead space would not have been compensated for. The resulting changes in tidal volume and minute volume, as measured by the Babylog 8000, were recorded together with the blood gas changes.

These measurements were completed in seven infants and were abandoned in the other five due to the need for intervention during the series.

\section{CALIBRATION AND ACCURACY}

The Fleisch pneumotachograph was initially calibrated against an Ohmeda electronic test unit accurate to $\pm 2 \%$ at flows of $2-25 \mathrm{1} / \mathrm{min}$ and with a resolution of $0.01 \mathrm{l} / \mathrm{min}$. The system was tested by syringing known volumes $( \pm 1 \%$ ) of air over the range $1-20 \mathrm{ml}$. The accuracy of volume measurement was $\pm 2-3 \%$.

Before use the pneumotachograph and manometer were allowed to warm up for 20 minutes and the flow and pressure offsets were set to zero against zero flow and atmospheric pressure. The drift over one hour was only $0.01 \mathrm{ml} / \mathrm{min}$ and so resetting to zero was not necessary during use.

In clinical use the Insight pressure readings were consistently in close agreement with the airway pressure measured by the Draeger Babylog ventilator: within $2-3 \%$ at peak pressures and within $10 \%$ at end expiratory pressures. The tidal volume measurements obtained by integration from the Fleisch pneumotachograph were consistently $10 \%$ greater than those derived by the same means from the Babylog flow sensor (a hot wire anemometer). This discrepancy was constant and remained so throughout the range of tidal volume measured.

The pneumotachograph was calibrated using room air. No correction factor was applied for differing fractional inspired oxygen $\left(\mathrm{FIO}_{2}\right)$ as each series of measurements was performed at constant $\mathrm{FIO}_{2}$ in individual infants and the error resulting from the use of higher $\mathrm{FIO}_{2}$ was cancelled out by the use of ratios.

\section{Results}

Thirty eight sets of measurements were made by $\mathrm{KMB}$ on 21 infants over the first few days of life, for as long as neuromuscular paralysis and mechanical ventilation were still necessary. The mean (SD) starting pressures were PIP $23.7(5.5) \mathrm{cm} \mathrm{H} \mathrm{H}_{2} \mathrm{O}$ and PEEP $3.2(0.8) \mathrm{cm}$ $\mathrm{H}_{2} \mathrm{O}$, and the mean (SD) starting tidal volume was $6.9(1.7) \mathrm{ml} / \mathrm{kg}$. The table gives the individual values for each infant.

The breath to breath variation in tidal volume over $30-60$ breaths at each setting was small. After each pressure change the tidal volume had nearly always returned to its original value when the initial settings were repeated. Occasionally, if the tidal volume did not regain its initial value immediately, it was

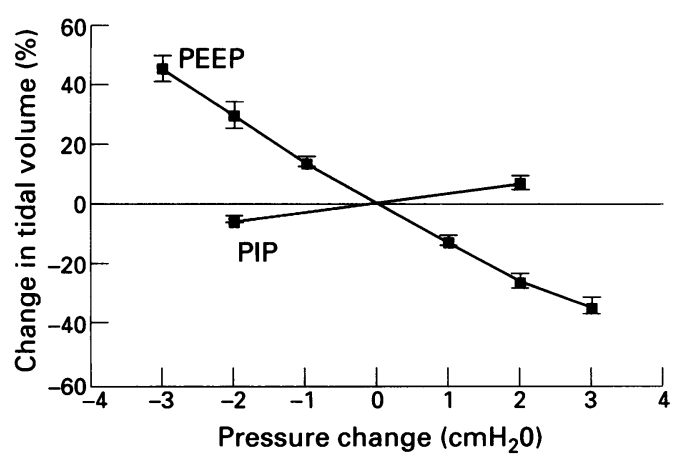

Figure 1 Change in tidal volume resulting from changes in PIP and PEEP. 95\% Confidence intervals are shown. 
measured again after a few minutes, and the sequence continued when it was within $3 \%$ of the initial measurement.

Figure 1 gives the percentage change in tidal volume resulting from individual manipulations of PEEP and PIP according to the protocol. Figure 2 shows in percentage terms the simultaneous changes in the minute volume and $\mathrm{PaCO}_{2}$ resulting from a $2 \mathrm{~cm} \mathrm{H}_{2} \mathrm{O}$ increase in PIP and a $1 \mathrm{~cm} \mathrm{H}_{2} \mathrm{O}$ decrease in PEEP. The correlation coefficient $(r)$ between the minute volume and $\mathrm{PaCO}_{2}$ was -0.74 $(p=0.003)$.

\section{Discussion}

Our findings clearly illustrate that alterations in PEEP result in a proportionally greater percentage change in the tidal volume than alterations in PIP of the same order of magnitude.

We have shown that reducing PEEP by $2 \mathrm{~cm}$ $\mathrm{H}_{2} \mathrm{O}$ results in a mean increase in tidal volume of $30 \%$, whereas a $2 \mathrm{~cm} \mathrm{H}_{2} \mathrm{O}$ increase in PIP results in a mean increase in tidal volume of only $7 \%$. Although we did not measure the effects of PEEP changes smaller than $1 \mathrm{~cm}$ $\mathrm{H}_{2} \mathrm{O}$ it is likely that a $0.5 \mathrm{~cm} \mathrm{H}_{2} \mathrm{O}$ reduction in PEEP equates to a $2 \mathrm{~cm} \mathrm{H}_{2} \mathrm{O}$ increase in PIP. This pronounced effect of PEEP on tidal volume was shown in all but one infant.

These observations reflect the non-linearity of lung compliance over the range of inflation encountered during intermittent positive pressure ventilation, with compliance increasing as end expiration is approached. The pressure-volume relation in the lung has often been referenced to the shape of the dynamic pressure-volume deflation curve. This may be misleading because any dynamic pressurevolume curve can only truly represent compliance at the points of zero flow, and so to illustrate our observations using pressurevolume relations, we would have to measure static compliance over the entire working range; clearly an impossible undertaking.

The one infant who behaved differently was one of the smallest and most premature in the study, weighing $680 \mathrm{~g}$ at 25 weeks' gestation. He developed pulmonary interstitial emphysema, became impossible to ventilate by conventional means, and died. In this infant alterations in PEEP had an insignificant effect on the tidal volume, which may possibly have been related to lung overdistension resulting from interstitial gas trapping.

Positive end expiratory pressure is usually used as a means of increasing the mean airway pressure and thus improving oxygenation. The effect of PEEP on tidal volume has implications for carbon dioxide exchange, as this is determined by the alveolar minute ventilation, in accordance with the alveolar ventilation equation $\left(\mathrm{PaCO}_{2}=\mathrm{VCO}_{2} /\right.$ alveolar minute volume $+\mathrm{K}$, where $\mathrm{VCO}_{2}$ is the rate of carbon dioxide production and $\mathrm{K}$ is a constant). This applies especially to very small preterm infants in whom alveolar ventilation may already be compromised by a disproportionately large anatomical dead space volume. The ratio of

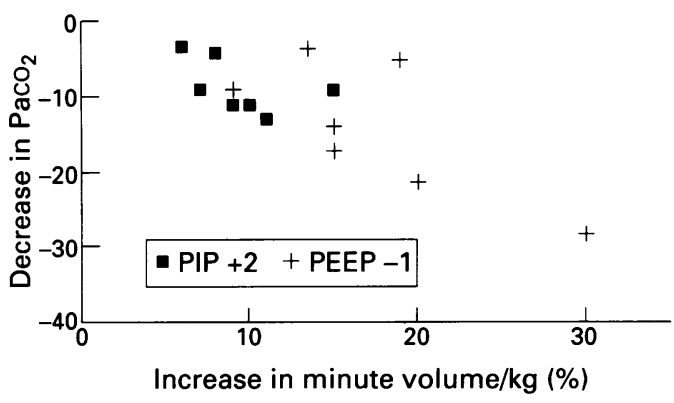

Figure 2 Relation between the percentage increase in minute volume and the percentage decrease in $\mathrm{PaCO}_{2}$. All the changes in minute volume were brought about by either a $2 \mathrm{~cm} \mathrm{H} \mathrm{H}_{2} \mathrm{O}$ increase in PIP or a $1 \mathrm{~cm} \mathrm{H} \mathrm{H}_{2} \mathrm{O}$ decrease in PEEP. No correction has been made for dead space.

dead space volume to tidal volume is an important determinant of alveolar ventilation and can be improved significantly by increasing the tidal volume or compromised by reducing the tidal volume.

We have shown that reductions in PEEP are as effective as increases in PIP at bringing about a reduction in $\mathrm{PaCO}_{2}$ for a comparable change in minute volume (fig 2 ). To prove this statistically we will need more data, but they are difficult data to collect.

Every infant tolerated increases in PIP of $2 \mathrm{~cm} \mathrm{H}_{2} \mathrm{O}$ and reductions in PEEP of the same magnitude, despite the accompanying decrease in mean airway pressure resulting from the latter. Some infants, however, particularly those with small tidal volumes and relatively compliant lungs, did not tolerate PEEP increases 1-2 $\mathrm{cm} \mathrm{H}_{2} \mathrm{O}$ very well and hence fewer of these measurements were completed. (This may have been partly due to the presence of the pneumotachograph without the compensation of bias flow.) Desaturation in nearly all these instances was easily overcome by a compensatory increase in $\mathrm{FIO}_{2}$.

In our clinical practice, since becoming impressed by the magnitude of the influence of PEEP on the tidal volume and $\mathrm{PaCO}_{2}$, we have tended to use PEEP levels of $2 \cdot 5-3 \cdot 5 \mathrm{~cm} \mathrm{H}_{2} \mathrm{O}$ in preference to our previous $4-6 \mathrm{~cm} \mathrm{H}_{2} \mathrm{O}$. This has allowed the use of substantially lower PIP in some infants while still gaining an equivalent tidal volume, which we hope might reduce pressure, or volume, trauma to the lung. In other instances, where arterial oxygenation has been a problem, it has not been possible to reduce PEEP and PIP without making compensatory changes to the waveform and inspiratory:expiratory ratio to maintain the mean airway pressure at the previous level. There are undoubtedly situations in which reducing PEEP is not feasible. In the context of the natural history of hyaline membrane disease, which is spontaneous improvement after 72 hours, this could become a critical manoeuvre during the period of recovery.

It is implicit that if the PEEP is reduced too far, and the functional residual capacity decreases below the closing capacity, then atelectasis will result and gas exchange will be affected. Animal work has suggested that some surfactants may require higher levels of PEEP than others for the clinical response to be maintained. ${ }^{5}$ Observations made over short intervals 
in animal models, however, may not necessarily be extrapolated to the clinical situation and should be interpreted with caution.

Our thesis is not to advocate the overenthusiastic reduction of PEEP but simply to highlight the use of small reductions of the order of $0.5-2 \mathrm{~cm} \mathrm{H}_{2} \mathrm{O}$. Despite a small decrease in mean airway pressure, we have actually seen an increase in $\mathrm{PaO}_{2}$ in some infants at constant $\mathrm{FIO}_{2}$. This may partly result from a reduction in alveolar carbon dioxide tension $\left(\mathrm{PACO}_{2}\right)$, according to the alveolar air equation $\left(\mathrm{PAO}_{2}=\mathrm{PIO}_{2}-\mathrm{PACO}_{2} / \mathrm{R}\right.$ where $\mathrm{PAO}_{2}=$ alveolar oxygen tension, $\mathrm{PIO}_{2}=$ oxygen tension in inspired gas, $\mathbf{R}=$ respiratory exchange ratio), from reversal of previous alveolar hypoventilation or possibly from cardiovascular effects. Conversely, we have become aware that a small increase in PEEP can result in a significant reduction in tidal volume, leading to higher carbon dioxide levels and alveolar hypoventilation.

We are grateful to the Yorkshire Regional Health Authority Locally Organised Research Scheme for supporting this study.

1 Gribetz I, Frank NR, Avery ME. Static volume-pressure relations of excised lungs of infants with hyaline membrane disease. F Clin Invest 1959; 38: 216-8.

2 Reynolds EOR, Roberton NRC, Wigglesworth JS. Hyaline membrane disease, respiratory distress, and surfactant membrane disease, respiratory distress,
deficiency. Pediatrics 1968; 42: 758-68.

3 Philips JB, Beale EF, Howard JE, Jaeger MJ, Eitzman DV Effect of positive end expiratory pressure on dynamic respiratory compliance in neonates. Biol Neonate 1980; 38: $270-5$.

4 Field D, Milner AD, Hopkin IE. Effects of positive end expiratory pressure during ventilation of the preterm infant. Arch Dis Child 1985; 60: 843-7.

5 Rider ED, Jobe AH, Ikegami M, Sun B Different ventilation strategies alter surfactant responses in preterm rabbits. f Appl Physiol 1992; 73: 2089-96. 